\title{
O PRINCÍPIO DO CONTRADITÓRIO É AFETADO QUANDO O JUIZ PROFERE A IMPROCEDÊNCIA LIMINAR DO PEDIDO?
}

\author{
Giovana de Oliveira Bianchi*
}

RESUMO

O presente artigo tem por objetivo, identificar se a improcedência liminar do pedido significa uma ofensa ao Princípio Constitucional do Contraditório. Construído por meio de pesquisas doutrinárias e análise de dispositivos de lei, busca o real objetivo desse recurso que o Novo Código de Processo Civil trouxe ao sistema jurídico brasileiro. A partir disso, serão feitas breves considerações sobre os princípios da celeridade e da economia processual, bem como o alinhamento jurisprudencial e tratamento isonômico para situações jurídicas idênticas.

Palavras-chave: Indeferimento liminar do pedido. Contraditório. Celeridade. Processo.

IS THE CONTRADITORY PRINCIPLE AFFECTED WHEN THE JUDGE PROVISES THE APPLICATION'S LIMITARY IMPROCEDENCE?

\begin{abstract}
The purpose of this article is to identify whether the injunction's unfounded request means an offense against the Constitutional Principle of Contradictory. Built through doctrinal research and analysis of legal provisions, it seeks the real purpose of this resource which the New Code of Civil Procedure brought to the Brazilian legal system. Therewith, brief considerations will be made on the principles of celerity and procedural economy, as well as the jurisprudential alignment and isonomic treatment for identical legal situations.

Keywords: Injunction request denial. Contradictory. Celerity. Process.
\end{abstract}

\section{INTRODUÇÃO}

A presente pesquisa científica discute se o princípio constitucional do contraditório é afetado quando há a sentença de improcedência liminar do pedido.

Para tanto, o trabalho foi subdividido em tópicos e em cada um deles são dissertados diversos aspectos sobre o tema, que juntos constroem uma base para que ao final se possa chegar a uma resposta sobre a indagação inicial, se o princípio é comprimido.

* Graduanda em direito da Universidade Metodista de São Paulo. 
A improcedência liminar do pedido divide opiniões entre os doutrinadores brasileiros, alguns dizendo que, ao juiz proferir tal decisão, não há ofensa ao contraditório; já outros afirmam que a ofensa ao princípio é nítida. Exatamente por essa divergência se faz necessário um estudo minucioso, o qual conste a origem, o conceito e o objetivo real do instrumento que o Código de Processo Civil trouxe ao ordenamento jurídico brasileiro.

O presente trabalho foi desenvolvido por análise doutrinária, que se utiliza dos referenciais teóricos dos doutrinadores Marcus Vinicius Rios Gonçalves, Humberto Theodoro Júnior, Elpídio Donizetti e Misael Montenegro Filho.

\section{DESENVOLVIMENTO:}

\section{CONSIDERAÇÕES INICIAIS SOBRE O CONTRADITÓRIO}

O princípio do contraditório está previsto na Constituição Federal de 1988, em seu artigo $5^{\circ}$, inciso LV, dando-lhe caráter fundamental. Dispõe que "aos litigantes, em processo judicial ou administrativo, e aos acusados em geral são assegurados o contraditório e ampla defesa, com os meios e recursos a ela inerentes".

Deste modo, é possível dizer que o direito ao contraditório é o direito que o acusado detém a se defender em face da acusação que lhe foi feita, podendo utilizar, para tanto, todos os meios de defesa admitidos em lei.

Como estamos no âmbito civil, o mesmo princípio também é previsto no artigo $9^{\circ}$ do CPC, determinando que "não se proferirá decisão contra uma das partes sem que ela seja previamente ouvida", sendo um dos princípios mais valorizados do diploma, estando localizado no capítulo das normas fundamentais do processo civil.

Nesse sentido, ensina Elpídio Donizetti:

O princípio do contraditório, assim como o do devido processo legal, apresenta duas dimensões. Em um sentido formal, é o direito de participar do processo, de ser ouvido. Mas essa participação há de ser efetiva, capaz de influenciar o convencimento do magistrado. Não adianta simplesmente ouvir a parte. A manifestação há de ser capaz de influenciar na formação da decisão. A seu turno, o juiz tem o dever correspondente de levar a manifestação na decisão. Essa é a perspectiva substancial do contraditório. (2017, p. 85).

Por esse trabalho se tratar de uma hipótese que poderia ou não afetar o princípio, é imprescindível ressaltar que ao juiz proferir uma sentença sem que as partes possam ter a oportunidade de se defender, o princípio é sim afetado, porém é necessário analisar se o contraditório é exercido em outra oportunidade, dando o efeito relevante ao processo. Portanto, em teoria o contraditório não seria afetado, pois mesmo não tendo sido realizado no ato originário, já teve ou terá a oportunidade de exercê-lo.

Por exemplo, se o recurso é cabível, as partes exercendo esse direito, o próprio recurso já não configuraria o contraditório? Porém, a questão é muito vaga, pois não faria sentido algum o princípio existir se o mesmo só pudesse ser utilizado em fase recursal. 
Para prosseguir, é necessário que tenhamos esses dois pontos em mente, com objetivo de analisar se haveria a possibilidade ou não de cabimento e em que hipótese seriam aceitas.

\section{DIVERGÊNCIAS DE UM CÓDIGO PARA O OUTRO}

O Código de Processo Civil trouxe ao ordenamento jurídico o instrumento chamado de "improcedência liminar do pedido", autorizando o julgamento imediato. Porém, não teve sua origem no mesmo.

O antigo Código já previa uma possibilidade, mas a mesma era vaga, deixando em aberto sobre quais tribunais se tratavam, prestigiando assim as jurisprudências de próprio juízo, portanto, entendendo que qualquer matéria controvertida que seja unicamente de direito e que haja sentença proferida em casos idênticos anteriores, já poderia se enquadrar na improcedência liminar do pedido.

Contudo, o novo CPC alterou substancialmente a técnica, para prever que o pedido pode ser julgado liminarmente improcedente quando contrariar enunciado de súmula do STF ou do STJ, acórdão proferido pelo STF ou pelo STJ em julgamento de recursos repetitivos (leia-se: o que representa consolidação de entendimento jurisprudencial sobre determinada questão), entendimento firmado em incidente de resolução de demandas repetitivas ou de assunção de competência ou enunciado de súmula de tribunal de justiça sobre direito legal.

Como percebemos, o novo CPC valoriza a jurisprudência, mas não uma jurisprudência oscilante ou predominante, mas a jurisprudência consolidada. (MONTENEGRO, FILHO, 2016, p. 314).

Marcus Vinicius Rios Gonçalves ensina que na época da implantação do dispositivo, essa autorização foi implantada de forma inédita no sistema jurídico brasileiro e como o código revogado era impreciso ao se tratar do tema:

A autorização concedida ao juiz nesse dispositivo era inédita, pois pela primeira vez permitia que ele julgasse o pedido do autor inteiramente improcedente, sem a citação do réu. Havia uma verdadeira sentença de mérito, proferida sem que o réu fosse chamado a manifestar-se. No entanto, esse dispositivo mereceu, enquanto vigorou, duras críticas dos processualistas, pois as causas de improcedência de plano estavam associadas a julgamentos anteriores proferidos pelo mesmo juízo, sem preocupação se tais decisões estavam ou não em consonância com a jurisprudência dos Tribunais Superiores. (2018, p. 453).

Já o novo dispositivo abriu o leque de cabimento, especificando os órgãos que caberiam tal sentença, tornando-o viável em cinco tópicos previstos no artigo 332 do CPC. Entretanto, persistiu nos moldes do rol taxativo, restringindo o cabimento somente nas possibilidades descritas em lei.

Sobre a questão no CPC, disserta Marcus Vinicius Rios Gonçalves:

As hipóteses de improcedência Liminar não estão mais associadas aos precedentes do próprio juízo, mas à existência de entendimento pacificado sobre a questão de direito em que se funda o pedido, nas hipóteses supramencionadas. (2018, p 453 - 454). 
Como foi dito anteriormente, o tema já era legislado pelo antigo CPC, porém, com algumas divergências. Uma das diferenças mais relevantes nesse momento do nosso estudo, é que o código revogado deixava ao juiz a faculdade de decidir se iria proferir de plano a improcedência ou se continuaria o processo, já mandando citar o réu. Sobre o assunto, explica melhor o doutrinador Marcus Vinicius Rios Gonçalves:

\begin{abstract}
A redação do art. 285-A do CPC de 1973 apenas permitia ao juiz dispensar a citação do réu e proferir de plano a sentença de total improcedência. Mas isso se ele assim o desejasse. Se não, poderia mandar citar o réu e, no momento oportuno, proferir o julgamento antecipado da lide.

O CPC atual, no art. 332, caput, faz uso do imperativo: nos casos por ele previstos, o juiz julgará liminarmente o pedido. Diante dos termos da lei, não resta dúvida sobre o caráter cogente do dispositivo. Verificadas as hipóteses dos incisos e do $\S 1^{\circ}$, do art. 332, o juiz deverá julgar liminarmente improcedente o pedido. Nenhuma nulidade, no entanto, haverá se o juiz não aplicar o dispositivo e mandar citar o réu. (2018, p. 455).
\end{abstract}

À vista disso, podemos concluir que temos duas mudanças de importância fundamental, a primeira é a aplicação facultativa se tornar obrigatória para os casos previstos lei. Antigamente o juiz analisava o caso e poderia ou não proferir a sentença de improcedência, mesmo que o caso se aplicasse inteiramente com o previsto em lei. O CPC vigente, traz o caráter obrigatório para o instrumento, retirando do juiz a faculdade de decidir se implantará ou não, se o caso pertence a uma das hipóteses presentes no rol taxativo do artigo 332, o juiz DEVE proferir a improcedência liminar do pedido. porém, "nenhuma nulidade, no entanto, haverá se o juiz não aplicar o dispositivo e mandar citar o réu. (GONÇALVES, 2018, p. 455)".

A segunda mudança, como já vimos neste tópico, é que é necessário existir entendimento pacificado sobre a questão de direito em que se funda o pedido, portanto, não sendo mais em juízos próprios, e sim em Tribunais Superiores, por exemplo, onde pacificaram um entendimento que por sua vez tornam jurisprudências que podem ser seguidas como exemplo em outros julgamentos. Um ponto importante de se ressaltar, é que no CPC vigente se mantém o requisito do pedido ter que versar sobre uma questão de direito, extinguindo-se, portanto, a hipótese de um pedido baseado em uma questão de fato poder ser proferida sentença de improcedência liminar.

Para que possamos entender como utilizar esse artifício, primeiramente veremos os princípios que dão a eles base legal para que assim possamos entender o motivo pelo qual o mesmo adentrou no sistema jurídico brasileiro.

\title{
2. PRINCÍPIOS NORTEADORES DA IMPROCEDENNCIA LIMINAR DO PEDIDO
}

Com o intuito de analisar se a improcedência Liminar do Pedido afeta o contraditório, é necessário ressaltar a finalidade para que foi criada e os princípios que a norteiam. 
Como é de conhecimento público, o judiciário brasileiro já há tempos vem enfrentando uma superlotação de processos. Pesquisa realizada em 2017 mostrou que constavam 80 milhões de processos ajuizados, sendo que a população brasileira estava em aproximadamente 207 milhões de pessoas, significando assim, que, por volta de $38,7 \%$ da população ajuizaram ações no Judiciário do país. Essa superlotação torna impossível que o processo seja célere, e consequentemente eficaz e tempestivo.

Por esse motivo o CPC vigente traz artifícios que diminuem a continuidade de processos que não teriam o regular prosseguimento por possuírem vícios insanáveis que violam dispositivos ou jurisprudências - porém, não uma jurisprudência oscilante ou predominante, mas a jurisprudência consolidada.

Ao colocar fim em demandas repetitivas, basicamente está sendo poupado o Judiciário da fase instrutória, que o faria gastar tempo e recursos para causas sem futuro, que não teriam a devida continuidade judicial. Como disserta Leonardo José Carneiro da Cunha, “a Fazenda Pública é ré em muitas demandas de massa, em demandas cuja solução é a mesma: ao decidir os primeiros casos, o juízo estará dando solução a todos os demais". (v. 39, p. 93-104).

Portanto, não há dúvidas de que um dos grandes objetivos do dispositivo é o alinhamento da jurisprudência nacional e a garantia do tratamento isonômico para situações jurídicas idênticas

A motivação para isso, origina-se do princípio da economia processual e valorização da jurisprudência. “O processo civil deve propiciar às partes uma Justiça rápida e barata, de modo a obter o máximo de resultado com o mínimo emprego possível de atividades judiciais. (DONIZETTI, 2017, p. 106)".

Relaciona-se também a razoável duração do processo e os meios que garantam a celeridade de sua tramitação, fixados pelo artigo $5^{\circ}$, LXXVIII da CF.

A solução dada pelo art. 332 favorece o princípio da isonomia e segurança jurídica, pois determina que todos os juízes julguem liminarmente improcedentes as pretensões, desde que presentes as hipóteses acima, todas elas - exceto a de prescrição e decadência - associadas à jurisprudência pacificada dos órgãos superiores". (GONÇALVES, 2018, p. 454).

Em vista disso, podemos afirmar que a improcedência liminar do pedido veio ao ordenamento jurídico como uma maneira de garantir a celeridade e assim economizar os recursos do judiciário. Também há a valorização jurisprudencial, fazendo com que entendimentos que já estão firmados barrem processos de ter continuidade, pois, como já violam entendimentos de tribunais, não possuem motivos plausíveis para que se gaste recursos. Assim sendo, não terão um futuro positivo ao autor da demanda. Por último, a incidência da improcedência em caráter liminar de casos idênticos aos que já possuem entendimentos pacificados e firmados garantem a isonomia e segurança jurídica, pois não haverá discrepância nos julgamentos que versem sobre o mesmo tema e intuito do pedido. 


\section{ARTIGO 332 DO CPC}

Para melhor entender se o princípio é de fato afetado, é necessário analisar mais a fundo as hipóteses que compõem o rol taxativo do artigo que o impõe. Vejamos:

Art. 332. Nas causas que dispensem a fase instrutória, o juiz, independentemente da citação do réu, julgará liminarmente improcedente o pedido que contrariar:

I - enunciado de súmula do Supremo Tribunal Federal ou do Superior Tribunal de Justiça;

II - acórdão proferido pelo Supremo Tribunal Federal ou pelo Superior Tribunal de Justiça em julgamento de recursos repetitivos;

III - entendimento firmado em incidente de resolução de demandas repetitivas ou de assunção de competência;

IV - enunciado de súmula de tribunal de justiça sobre direito local.

$\S 1^{\circ} \mathrm{O}$ juiz também poderá julgar liminarmente improcedente o pedido se verificar, desde logo, a ocorrência de decadência ou de prescrição. (Código de Processo Civil, Lei n. 13.105, de 16-3-2015, SARAIVA JUR, $3^{\text {a }}$ edição, $2^{\mathrm{a}}$ tiragem, 2018, p. 121)

O artigo elenca 5 hipóteses de cabimento, como visto acima, portanto, não há de se falar que o instituto da Improcedência Liminar do Pedido é abrangente pois se limita exclusivamente a essas hipóteses previstas em lei.

Já na perspectiva de Donizetti, o conteúdo da sentença em si não possui mais valor, e sim o órgão que a profere:

Ressalte-se que o CPC/1973 (art. 285A) condicionava essa decisão apenas à hipótese de existência, no juízo, de sentença de total improcedência proferida em casos idênticos. A sentença proferida no mesmo juízo, pode-se dizer, que servia de parâmetro para futuras decisões de improcedência liminar. Agora, para tanto, a sentença não tem mais valor. Quem tem status para firmar precedente são os tribunais superiores e, no caso do IRDR, os tribunais de justiça e os tribunais regionais federais. Manda quem pode e obedece quem tem juízo. (2017, p. 87).

Porém, como já vimos anteriormente que não é qualquer jurisprudência que tem a força de tornar um pedido improcedente, a mesma deve ser consolidada pelos tribunais em questão.

Por outro lado, é de grande valia ressaltar, de acordo com os ensinamentos de Paulo Cezar Pinheiro Carneiro e Humberto Dalla Bernardina de Pinho (2015, p. 187-188)., que:

O artigo traz importante regramento sobre a improcedência liminar do pedido, sanando dúvidas que havia na vigência do art. 285-A do Código revogado. Aplica-se o artigo a causas que dispensem dilação da instrução, portanto, não apenas matéria de direito, mas também matéria de fato notória. Pertinente o aprimoramento da norma, excluir o embasamento da decisão em precedentes do próprio juízo - como era no Código revogado - passando a definir como fundamentos possíveis para o julgamento de improcedência liminar, enunciados, súmulas e julga- 
mentos em recursos repetitivos e incidentes de resolução de demandas repetitivas ou de assunção de competência.

Portanto, não há de se falar em inconstitucionalidade do artigo, pois não afronta nenhuma das garantias fundamentais, nem mesmo dizer que a sentença na qual a improcedência se apoia é vaga, visto que, além de se tratar de tribunais superiores (e afins), a mesma é firmada e consolidada de forma jurisprudencial.

Vimos que o artigo traz 4 hipóteses que se tratam de jurisprudências de tribunais, porém, também temos como hipótese de cabimento o $\$ 1^{\circ}$ do CPC, que se trata da prescrição e decadência. Sobre esta hipótese explica Elpídio Donizetti:

Prescrição é a perda da pretensão à reparação de um direito violado, em razão da inércia do seu titular, durante o lapso temporal estipulado pela lei. A prescrição aniquila somente a pretensão, não alcançando o direito constitucional de ação. Passados seis meses a contar da data da apresentação, o cheque perde sua força executiva. (art. 59 da Lei n ${ }^{0} 7.357 / 1985$ ). Decadência é a perda do próprio direito pelo não exercício no prazo estabelecido pela lei. A decadência alcança o direito potestativo, que pode se referir ao direito material ou a um dado procedimento (direito à via do mandado de segurança, por exemplo). (2017, p. 614).

\section{HÁ OFENSA AO PRINCÍPIO DO CONTRADITÓRIO?}

Como já foi visto no presente trabalho, a Improcedência Liminar do Pedido foi implantada com o objetivo principal de garantir a celeridade a processos que não possuem um histórico jurisdicional positivo ao autor da ação. Contudo, o princípio da celeridade pode passar por cima do princípio do contraditório?

Há alguns doutrinadores que defendem que o contraditório é, sim, afetado, como Elpídio Donizetti, que sustenta:

Temos que ter em mente que a celeridade é sinônimo de efetividade. Mas a efetividade há que ser virtuosa, ou seja, a decisão deve ser rápida sem comprometer os postulados do processo. A pressa sem qualquer preocupação com os demais princípios que norteiam o princípio constitui uma efetividade malsã, contrária à tão propalada exigência de um processo justo. Em certos casos, matar uma ação no nascedouro, sob a pretensa materialização do princípio da celeridade, constitui a mais arrematada injustiça. (2017, p. 88).

Portanto, o doutrinador afirma que ao decidir liminarmente, o juiz retira tanto do autor como do réu faculdades importantes ao processo, conduzindo a falsidade dos fatos contidos na petição inicial, consequentemente causando uma injustiça, tanto para o autor que não pode sustentar a veracidade de sua ação, quanto ao réu que não teve a oportunidade de influir, com a prática de atos posteriores à petição inicial.

Daí vem a questão: o contraditório já não é exercido na petição inicial realizada pelo autor, quando expôs os motivos de fato ou de direito que o fizeram ajuizar a ação, ou por existir a liminar, cabendo recurso - o próprio agravo não seria o contraditório? 


\section{PRESERVAÇÃO DO CONTRADITÓRIO}

Em primeiro lugar é importante ressaltar que ao identificar que na demanda há incidência das hipóteses do artigo 332, o juiz deve ouvir o autor, respeitando o artigo $9^{\circ}$ e $10^{\circ}$. Porém,"não há a necessidade de que ouça o réu, que nem sequer foi citado". (GONÇALVES, 2018, p. 65).

Entretanto, essa oitiva se trata de mera formalidade, pois se no rol taxativo do 332 do CPC está previsto o caso concreto, em se tratando de demanda repetitiva ou prescrição ou decadência, não há nada que o autor faça para impedir a prolação da sentença de improcedência total. Isso só ocorre para que não decorra ofensa ao princípio da não surpresa, e que dessa maneira o autor fique preparado para propor apelação no prazo previsto em lei, se assim o desejar.

A maioria dos doutrinadores pesquisados afirmam que o contraditório não é afetado. Marcus Vinicius Rios Gonçalves já afirma: “Não há nenhuma inconstitucionalidade na dispensa da citação do réu, na hipótese do artigo 332. É certo que não haverá contraditório, mas disso não resultará prejuízo". (2018, p. 455).

É necessário ressaltar novamente que tal artifício só poderá ser utilizado quando a causa dispensar a fase instrutória e que o mesmo esteja presente em qualquer uma das hipóteses do art. 332, I a IV, ou no $\$ 1^{\circ}$ do dito artigo, que versam sobre a total improcedência, pois, só assim se pode dispensar a citação do réu sem sofrer nenhum prejuízo - portanto, não ferindo o princípio do contraditório.

Portanto, na linha de raciocínio do doutrinador, não é que o contraditório é ofendido, pois, nesta fase do processo o contraditório não irá ocorrer mesmo. Porém, nenhum prejuízo decorrerá da sua não ocorrência, dado que as hipóteses de cabimento compõem um rol taxativo, que em fase preliminar deve ser seguido para que se alcance a efetividade dos princípios da celeridade e economia processual. Não há, portanto, razões plausíveis para a continuidade da demanda, justamente por se tratarem de situações que já foram fixadas como improcedentes.

O próprio doutrinador pontua:

A aplicação do dispositivo atribui ao juiz a possibilidade de julgar mais rapidamente processos que versam sobre determinada questão jurídica que, por sua repetição e multiplicidade, deram ensejo à edição de súmula ou ao julgamento repetitivo. São conhecidas as situações em que determinadas teses jurídicas dão ensejo a uma multiplicação de processos, nos quais se discute a mesma questão de direito. Para acelerar-lhes o julgamento é que o novo dispositivo foi introduzido. (GONÇALVES, 2018, p. 455). (Grifos não originais).

A sentença proferida pelo juiz deve conter a fundamentação adequada, indicando qual dos incisos do artigo 332 o pedido declarado improcedente se funda, demonstrando também que o caso que o ensejou a declará-la se adequa perfeitamente à demanda, sob pena da sentença ser considerada não fundamentada, dando, portanto, cabimento aos embargos de declaração.

No entanto, por se tratar de liminar, o Código de Processo Civil nos traz a oportunidade de recorrer dessa decisão de improcedência; assim, o autor irá exercer o 
seu direito de contraditório, bem como o da ampla defesa, por meio da apelação. E o réu, apresentando suas contrarrazões de apelação, desempenhará o mesmo papel que exerceria em contestação, configurando assim o seu veículo de defesa.

\section{RECURSO CABÍVEL CONTRA A SENTENÇA DE IMPROCEDÊN- CIA LIMINAR}

O autor, insatisfeito com a decisão de improcedência liminar do pedido, poderá apelar no prazo de 15 dias. O juiz, por sua vez receberá a apelação e terá a oportunidade utilizar o juízo de retratação, se assim o preferir, para o que terá 5 dias para realizá-la (art. 332, § $3^{\circ}$ ) - ocorrendo-a, o processo será retomado, com a determinação de citação do réu para contestar. Tem, portanto, o curso do procedimento comum em primeiro grau. Humberto Theodoro Júnior ensina:

O julgamento liminar, nos moldes traçados pelo art. 332, não agride o devido processo legal, no tocante às exigências do contraditório e ampla defesa. A previsão de um juízo de retratação e do recurso de apelação assegura ao autor, com a necessária adequação, um contraditório suficiente para o amplo debate em torno da questão de direito enfrentada e solucionada in limine litis. (2018, p. 808).

Se o juiz decidir que sua decisão está correta, e com a devida fundamentação nos moldes do dispositivo de lei que cabe a improcedência limitar total, e não se retratar, deverá citar o réu antes mesmo de enviar os autos ao tribunal, para que o mesmo possa responder ao recurso, como determina o artigo 332, $\S 4^{\circ}$.

Sobre a retratação ou não retração da sentença podemos analisar o que pontua Humberto Theodoro Júnior:

Se o juiz retratar sua decisão liminar, o feito terá curso normal, e o réu
usará livremente do direito de contestar a ação e produzir os elementos
de defesa de que dispuser, dentro do procedimento completo por que
tramitará a causa. Se a hipótese for de manutenção da sentença, ao réu
será assegurada a participação no contraditório por meio das contrar-
razões da apelação e, eventualmente, de contestação se o tribunal não
mantiver a decisão liminar “. (2018, p. 808).

CONCLUSÃO

Diante de todo o exposto, conclui-se que há uma divergência doutrinária em relação ao tema. Porém, a maioria dos doutrinadores que foram pesquisados se mantém com a linha de raciocínio em que afirmam que o princípio do contraditório não é afetado com a improcedência liminar do pedido, dando esse direito constitucional às partes por meio de outros mecanismos dentro do processo. Portanto, se a parte interessada não concordar com a decisão que tornou o pedido liminarmente improcedente, poderá, se for da sua vontade, interpor o recurso cabível.

Porém, antes de simplesmente dizer que não há o contraditório, uma vez proferida a improcedência liminar, colocando fim a fase instrutória, é importante analisar o fim para que o artifício foi criado. 
O motivo da inserção desse instrumento no ordenamento jurídico é justamente garantir o princípio da celeridade, bem como a economia processual. Portanto, tendo como objetivo principal retirar o acúmulo de processos do judiciário, cujas demandas já possuem entendimentos/jurisprudências consolidadas por tribunais superiores, e/ ou pertencem às outras hipóteses cabíveis no rol TAXATIVO do artigo 332, CPC.

É de grande valia ressaltar que, apesar de o juiz ter essa autonomia, deve fundamentar sua decisão, apontando e justificando qual item das hipóteses elencadas no artigo se adequa ao caso concreto, sob pena da sentença ser considerada não fundamentada - abrindo o leque recursal para os embargos de declaração. Dessa maneira, não há outra decisão a ser tomada por parte do Judiciário senão a de seguir a lei, proferindo a improcedência liminar do pedido, quando o mesmo pertencer às hipóteses de cabimento - não há outra alternativa.

Por fim, entende-se que o contraditório pode até não existir nessa etapa processual, como disserta Marcus Vinicius Rios Gonçalves; porém, esse vácuo não traz prejuízo para as partes, exatamente por se tratar de decisão liminar, existindo a possibilidade de interposição da apelação pela parte autora, e resposta pela parte ré por meio das contrarrazões. O réu, de maneira nenhuma, será prejudicado por não ter oportunidade preliminar de apresentar sua resposta por meio de contestação; mas, por sua vez, só irá adquirir benefícios, na medida em que obterá sentença favorável, sem ao menos retrair algum ônus ou despesa processual.

\section{REFEREANCIAS}

BRASIL. Constituição da República Federativa do Brasil. 1988

BRASIL. Código de Processo Civil Brasileiro. 1973.

BRASIL. Código de Processo Civil Brasileiro. 2015, CPC, SARAIVA JUR, $3^{\circ}$ edição, $2^{a}$ tiragem, 2018.

GONÇALVES, Marcus Vinicius Rios. Novo curso de direito processual civil - 9. Ed - São Paulo: Saraiva Educação, 2018.

THEODORO JÚNIOR, Humberto. Curso de direito processual civil - 59. ed. rev., atual. e ampl. - Rio de Janeiro: Forense, 2018.

DONIZETTI, Elpídio. Curso didático de direito processual civil - 20. ed. rev., atual. e ampl. - São Paulo: Atlas, 2017.

MONTENEGRO FILHO, Misael. Curso de direito processual civil - 12. ed. reform. e atual. - São Paulo: Atlas, 2016.

CUNHA, Leonardo José Carneiro da. Primeiras Impressões sobre o art. 285-A do CPC (Julgamento Imediato de Processos repetitivos: uma Racionalização para as demandas de Massa). Revista Dialética de Direito Processual, São Paulo, v. 39, p. 93-104, jun. 2006.

CARNEIRO, Paulo Cezar Pinheiro, PINHO, Humberto Dalla Bernardina de. Novo Código de Processo Civil Lei 13.105, de 16 de março de 2015, anotado e comparado. Rio de Janeiro: Forense, 2015.

CNJ - Disponível em < https://www.cnj.jus.br/programas-e-acoes/priorizacao-do-1o-grau/dados-estatisticos-priorizacao/> Acesso em: 7 de junho de 2020. 